\title{
产业体系成熟度评价方法研究
}

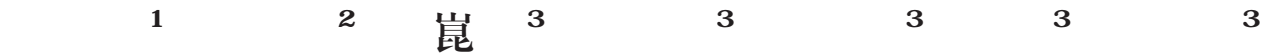 \\ (1. 中国航天科技集团有限公司，北京 100048；2. 中国空间技术研究院，北京 100094； \\ 3. 中国航天系统科学与工程研究院, 北京 100048)
}

\begin{abstract}
摘要: 本文提出产业体系成熟度概念, 新增包括自主可控能力和行业主导能力在内的产业安全可控程度评价因素, 构建相应 的评价准则和评价模型。这一方法考虑了技术、设备、资金、产品等产业要素供给是否具有独立自主性, 评价结果可以反映 一国产业安全可控程度的基本状况。应对我国战略性新兴产业宏观研究亟需, 完成了 25 个新兴产业方向的产业体系成熟度 评价分析。结果表明, 对于研究涉及的 25 个新兴产业方向, 产业体系进入发展阶段或成熟阶段的产业方向数量相对较少, 且多数产业方向的安全可控程度评价结果不佳。具体而言, 仅有纯电动汽车产业的产业体系处于成熟阶段且产业安全可控程 度强; 轻薄化增强现实 ( $\mathrm{AR}$ ) 显示模组, 生物医药、生物反应器及成套装置, 应急疫苗研发与制备技术 3 个产业方向的产 业体系成熟程度偏低, 自主可控能力与行业主导能力均较弱。我国不少新兴产业方向在产业安全可控方面的短板较为突出, 在加快构建自主可控的现代产业体系过程中，应注重提高本国资本对核心技术、原材料、标准、品牌等要素的掌控能力。
\end{abstract}

关键词: 产业体系成熟度; 战略性新兴产业; 评价方法; 产业安全可控

中图分类号：T-01 文献标识码：A

\section{Assessment Method of Industrial System Maturity Levels}

\author{
Wang Liheng ${ }^{1}$, Zhou Zhicheng ${ }^{2}$, Wang Kunsheng ${ }^{3}$, Lu Chunhua ${ }^{3}$, Wang Hainan ${ }^{3}$, \\ Cui Jian $^{3}$, Ma Xuemei ${ }^{3}$
}

(1. China Aerospace Science and Technology Corporation, Beijing 100048, China; 2. China Academy of Space Technology, Beijing 100094, China; 3. China Aerospace Academy of Systems Science and Engineering, Beijing 100048, China)

\begin{abstract}
This paper proposes the concept of industrial system maturity level, and introduces a new factor, namely, industry security and controllability level (ISCL), which further comprises the autonomous and controllable ability and the industry leading ability. Corresponding assessment criteria and model are also constructed. This method takes into account whether the supply of industrial elements such as technology, equipment, capital, and products are independent. The assessment results can reflect the basic state of a country's ISCL. In response to the urgent need for macro-research on China's strategic emerging industries, this study assessed and analyzed the industrial system maturity levels of 25 emerging industry directions. It shows that, among the 25 directions, the industrial systems of only few industrial directions have entered into a developing or mature stage, and most industrial directions got unsatisfactory assessment results for their ISCLs. Specifically, only the industrial system of the battery electric vehicle industry is in the mature stage and has a high ISCL. The ISCLs of light-weight augmented reality display module, biomedical bioreactor and
\end{abstract}

收稿日期 : 2020-01-02; 修回日期 : 2020-03-10

通讯作者：王礼恒，中国航天科技集团有限公司高级技术顾问，中国工程院院士，研究方向为导弹动力技术和航天工程管理; E-mail:1ch1600@126.com

资助项目：中国工程院咨询项目“新兴产业发展战略研究（2035）”(2018-ZD-12)

本刊网址： www.engineering.org.cn/ch/journal/sscae 
complete equipment, and emergency vaccine research and preparation, are relatively low; and the autonomous and controllable ability as well as the industry leading ability of these three industrial directions are weak. Many emerging industries in China have prominent shortcomings in the ISCL. In the process of accelerating the construction of an independent and controllable modern industrial system, attention should be paid to improving the domestic capital's control over the core technologies, raw materials, standards, brand, and other elements.

Keywords: industrial system maturity level; strategic emerging industries; assessment method; industry security and controllability level (ISCL)

\section{一、前言}

我国积极参与全球经济合作，提出了加快经济 发展方式转变的重大部署, 将战略性新兴产业作为 产业转型升级的重要方向。科学客观地评价新兴技 术研究与产业化发展的状况, 全面准确地把握产业 成熟规律并合理预测发展趋势, 成为新兴产业发展 规划的重要课题。

成熟度已成为评价与衡量产业发展状态的有 效方法, 其概念起源于 20 世纪 70 年代美国国家航 空航天局 (NASA) 开展的技术成熟度 (TRL) 研 究 [1]。目前技术成熟度评价标准已基本成熟, 评价 方法和实施程序也已形成规范 [2]。国内外学者将 技术成熟度评价方法推广到产品和市场经济领域。 2003 年以来, 我国航天领域开始研究产品成熟度 (PRL) [3], 主要是为了适应航天科研生产由单件研 制向小批量生产转型的趋势变化; 针对航天产品特 殊性和小子样研制伴生的问题, 构建了航天单机产品 8 级框架模型。根据工程发展的实际需求, 又陆续发 展了制造成熟度 (MRL) [4]、集成成熟度 [5]、软件 能力成熟度 [6] 和人员队伍成熟度 [7] 等评价方法。

现有的文献 [8] 沿着 TRL、MRL、PRL 的理论 发展方向深化探索, 提出了产业成熟度概念, 采用 定性和定量相结合的方法构建了产业成熟度评价模 型。首先对技术、制造方面的成熟状况进行评价, 而后集成出 PRL, 结合市场成熟度 (MML) 评价 结果, 形成产业成熟度的综合评价结果 (产业成熟 度等级)。在我国战略性新兴产业的系列咨询研究 中 [9], 利用相关方法完成了产业成熟度评价工作, 挖掘具体产业方向面临的制约要素、发展需求、潜 在风险和产业预期成熟时间等关键因素, 为新兴产 业培育与发展研究提供了基础性支持。

应对世界产业竞争不断加剧、中美贸易摩擦长
时间存在、科技和产业自主可控的重要性加强等新 形势需求, 我国亟需构建自主可控的现代产业体系, 而原先使用的产业成熟度评价方法暴露出一定的局 限性：原始方法注重一国某个具体产业的整体繁荣 程度，没有考虑该产业中技术、设备、资金以及产 品等要素的供给是否具有独立自主性, 因而评价结 果难以反映一国产业的安全可控程度。以此为研究 切入点, 本文新增包括自主可控能力和行业主导能 力在内的产业安全可控程度评价因素, 构建新的产 业体系成熟度评价模型, 并在多个新兴产业方向开 展评价和应用。

\section{二、产业体系成熟度评价方法}

\section{（一）模型构成}

基于产业成熟度模型的基本框架 [8], 结合加 快构建自主可控的现代化产业体系的战略需求及顶 层要求, 本文新增了产业安全可控度 (ISCL) 评价 指标, 构建了产业体系成熟度评价模型（见图 1)。 其中, TRL、MRL、PRL 和 MML 沿用原有概念和 评价指标。

ISCL 用于度量和评价产业安全可控的程度, 主要从自主可控能力和行业主导能力两方面进行评 价。自主可控能力评价涉及核心原材料自主水平、 核心技术自主水平、关键基础设备自主水平、内资 控股能力; 行业主导能力评价涉及国内品牌市场影 响力、国内产品销售对外出口依存度、行业标准制 定能力。ISCL 具体评价标准见表 1 。

\section{（二）指标集成关系}

产业体系成熟度评价模型涵盖了 ISCL、PRL、 产业成熟度和产业体系成熟度 4 层集成关系。 (1) ISCL 由自主可控能力和行业主导能力集成得 


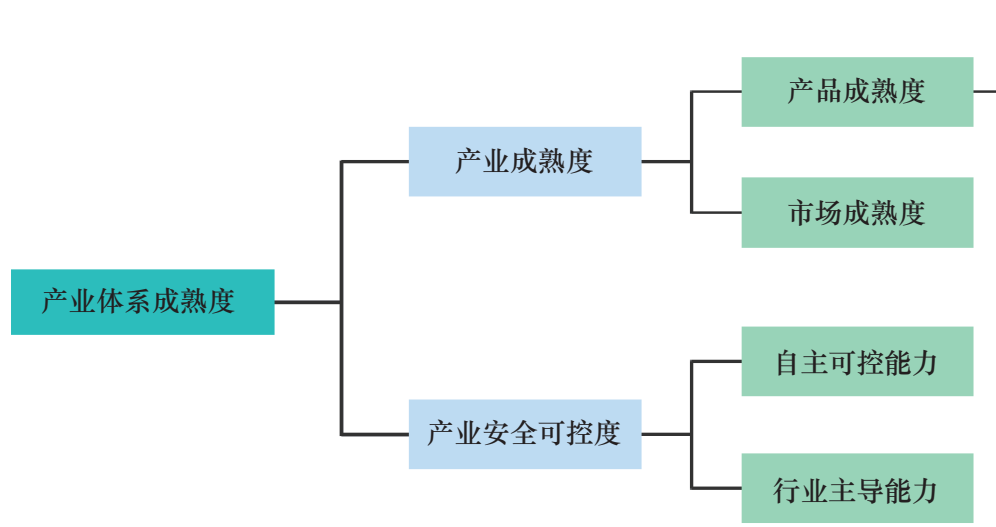

技术成熟度

图 1 产业体系成熟度评价模型结构示意图

表 1 产业安全可控度指标及定义

\begin{tabular}{|c|c|c|c|}
\hline 一级 & $\begin{array}{l}\text { 二级 } \\
\text { 指标 }\end{array}$ & $\begin{array}{l}\text { 发展 } \\
\text { 阶段 }\end{array}$ & 发展阶段定义 \\
\hline \multirow{12}{*}{$\begin{array}{l}\text { 自主 } \\
\text { 可控 } \\
\text { 能力 }\end{array}$} & \multirow{3}{*}{$\begin{array}{l}\text { 核心原材料 } \\
\text { 自主能力 }\end{array}$} & 1 (弱) & 国内基本上不具有核心原材料自主生产能力，核心原材料严重依赖进口 \\
\hline & & 2 (中) & $\begin{array}{l}\text { 国内具有一定的核心原材料自主生产能力, 国内厂商与国外厂商存在一定的竞争关系, } \\
\text { 但国内水平与国际水平总体上还有差距 }\end{array}$ \\
\hline & & 3 (强) & $\begin{array}{l}\text { 国内具有相当的核心原材料自主生产能力, 性能达到国际领先水平; 尽管一些厂商基于 } \\
\text { 自身偏好或者商业动机选择从国外进口, 但国内核心原材料供给完全可以满足市场需求 }\end{array}$ \\
\hline & \multirow{3}{*}{$\begin{array}{l}\text { 核心技术 } \\
\text { 自主能力 }\end{array}$} & 1 (弱) & 国内基本上不具有核心技术自主研发能力，核心技术严重依赖国外输入 \\
\hline & & 2 (中) & $\begin{array}{l}\text { 国内具有一定的核心技术自主研发能力，国内厂商与国外厂商存在一定的竞争关系，但 } \\
\text { 国内水平与国际水平总体上还有差距 }\end{array}$ \\
\hline & & 3 (强) & $\begin{array}{l}\text { 国内具有相当的核心技术自主研发能力, 技术达到国际领先水平; 尽管一些厂商基于自身 } \\
\text { 偏好或者商业动机选择从国外引进，但国内核心技术供给完全可以满足市场需求 }\end{array}$ \\
\hline & \multirow{3}{*}{$\begin{array}{l}\text { 关键基础 } \\
\text { 设备自主 } \\
\text { 能力 }\end{array}$} & 1 （弱） & 国内基本上不具有关键基础设备自主提供能力，关键基础设备严重依赖从国外进口 \\
\hline & & 2 (中) & $\begin{array}{l}\text { 国内具有一定的关键基础设备自主提供能力, 国内厂商与国外厂商存在一定的竞争关系, } \\
\text { 但国内水平与国际水平总体上还有差距 }\end{array}$ \\
\hline & & 3 (强) & $\begin{array}{l}\text { 国内具有相当的关键基础设备自主提供能力, 性能达到国际领先水平; 尽管一些厂商基于 } \\
\text { 自身偏好或者商业动机选择从国外进口, 但国内关键基础设备供给完全可以满足市场需求 }\end{array}$ \\
\hline & \multirow{3}{*}{$\begin{array}{l}\text { 内资控股 } \\
\text { 能力 }\end{array}$} & 1 (弱) & 行业资金基本上由国外投入，主要厂商的股权少部分由内资把控（30\% 以下） \\
\hline & & 2 (中) & 行业资金一定程度上由国外投入，主要厂商的股权一定程度上由内资把控（30\% 70\%) \\
\hline & & 3 (强) & 行业资金基本上由国内投入，主要厂商的股权基本上由内资把控（70\% 以上） \\
\hline \multirow{9}{*}{$\begin{array}{l}\text { 行业 } \\
\text { 主导 } \\
\text { 能力 }\end{array}$} & \multirow[t]{3}{*}{$\begin{array}{l}\text { 国内品牌 } \\
\text { 市场影响力 }\end{array}$} & 1 (弱) & $\begin{array}{l}\text { 国内品牌在行业内基本上不具有和国外品牌竞争的实力, 无论是市场份额和行业影响力都 } \\
\text { 明显弱于国外品牌 }\end{array}$ \\
\hline & & 2 (中) & 国内品牌占据一定的市场份额，但是中高端市场仍然以国外品牌占据为主 \\
\hline & & $3($ 强 $)$ & $\begin{array}{l}\text { 国内品牌具有相当的行业影响力, 尽管一些消费者基于个人偏好仍然选择国外品牌, 但 } \\
\text { 国内品牌在中高端市场完全可以供给同等品质的产品 }\end{array}$ \\
\hline & \multirow{3}{*}{$\begin{array}{c}\text { 国内产品 } \\
\text { 销售对外 } \\
\text { 出口依存度 }\end{array}$} & 1（弱） & 国内品牌产品的销售严重依赖于对外出口（70\% 以上） \\
\hline & & 2 (中) & 国内品牌产品的销售一定程度上依赖于对外出口（30\% 70\%） \\
\hline & & $3($ 强 $)$ & $\begin{array}{l}\text { 国内市场对国内品牌产品具有巨大的消费需求, 且国内厂商亦可根据国际市场行情进行 } \\
\text { 出口决策 }\end{array}$ \\
\hline & \multirow{3}{*}{$\begin{array}{l}\text { 行业标准 } \\
\text { 制定能力 }\end{array}$} & 1 (弱) & 行业标准的制定能力基本上被国外把控，国内厂商基本无话语权 \\
\hline & & 2 (中) & $\begin{array}{l}\text { 国内厂商在国际行业标准制定的过程中有一定的投票权或话语权, 但仍无主导行业标准的 } \\
\text { 能力 }\end{array}$ \\
\hline & & $3($ 强） & $\begin{array}{l}\text { 国内厂商在国际行业标准制定的过程中有相当的投票权或话语权, 具有较强的主导行业 } \\
\text { 标准的能力 }\end{array}$ \\
\hline
\end{tabular}


到, 划分为弱、较弱、中和强 4 个等级 (见表 2)。 (2) PRL 由 TRL 和 MRL 集成得到, 可划分为 5 个等 级: 1 级 (概念产品)、 2 级 (实验室产品)、 3 级 (工 程化产品)、4 级 (示范产品) 和 5 级 (市场产品) (见表 3 )。(3)产业成熟度由 PRL 和 MML 集成得到,
可划分为 4 个等级: 1 级 (萌生)、 2 级 (培育)、 3 级 (发展) 和 4 级 (成熟) (见图 2)。(4)产业体系 成熟度由产业成熟度和 ISCL 集成得到, 可划分为 4 个等级: 1 级 (萌生)、 2 级 (培育)、3 级 (发展) 和 4 级（成熟）(见图 3)。

表 2 产业安全可控度的集成关系

\begin{tabular}{lll}
\hline 属性 & 发展阶段 & \\
\hline 自主可控能力 & A1 (弱) & 存在评价结果为 1 的二级指标 \\
& A2 (中) & 不存在评价结果为 1 的二级指标, 但并非所有二级指标评价结果都为 3 \\
& A3 (强) & 所有二级指标评价结果都为 3 \\
行业主导能力 & I1 (弱) & 存在评价结果为 1 的二级指标 \\
& I2 (中) & 不存在评价结果为 1 的二级指标, 但并非所有二级指标评价结果都为 3 \\
& I3 (强) & 所有二级指标评价结果都为 3 \\
产业安全可控度 & ISCL1 (弱) & 两个一级指标评价结果都为 1 \\
& ISCL2 (较弱) & 两个一级指标中, 一个为 1, 另一个为 2 或 3; 或两个一级指标评价结果都为 2 \\
& ISCL3 (中) & 两个一级指标中, 一个为 2, 一个为 3 \\
& ISCL4 (强) & 两个一级指标评价结果都为 3 \\
\hline
\end{tabular}

注：一级指标为自主可控能力和行业主导能力, 二级指标指表中第 3 列所列指标; A 代表自主可控能力, I 代表行业主导能力。

表 3 产品成熟度的集成关系

\begin{tabular}{lccc}
\hline 产品成熟度 & 产品阶段 & 技术成熟度 & 制造成熟度 \\
\hline PRL 1 & 概念产品 & TRL 1 & MRL 1 \\
& & TRL 2 & MRL 2 \\
& & TRL 3 & MRL 3 \\
PRL 2 & 实验室产品 & TRL 4 & MRL 4 \\
& & TRL 5 & MRL 5 \\
& & TRL 6 & MRL 6 \\
PRL 3 & 工程化产品 & TRL 7 & MRL 7 \\
& & & MRL 8 \\
PRL 4 & TRL 8 & MRL 9 \\
PRL 5 & 示范产品 & TRL 9 & MRL 10 \\
\hline
\end{tabular}

\begin{tabular}{|l|c|c|c|c|c|c|}
\hline 产品成熟度 & 1 级 & 2级 & 3级 & 4级 & 4级、5级 & 5级 \\
\hline 市场成熟度 & & & 1 级 & 2级 & 3 级 \\
\hline 产业成熟度 & 1级 & 2级 & 3级 & 4级 \\
\hline
\end{tabular}

产业发展阶段

图 2 产业成熟度集成方法 


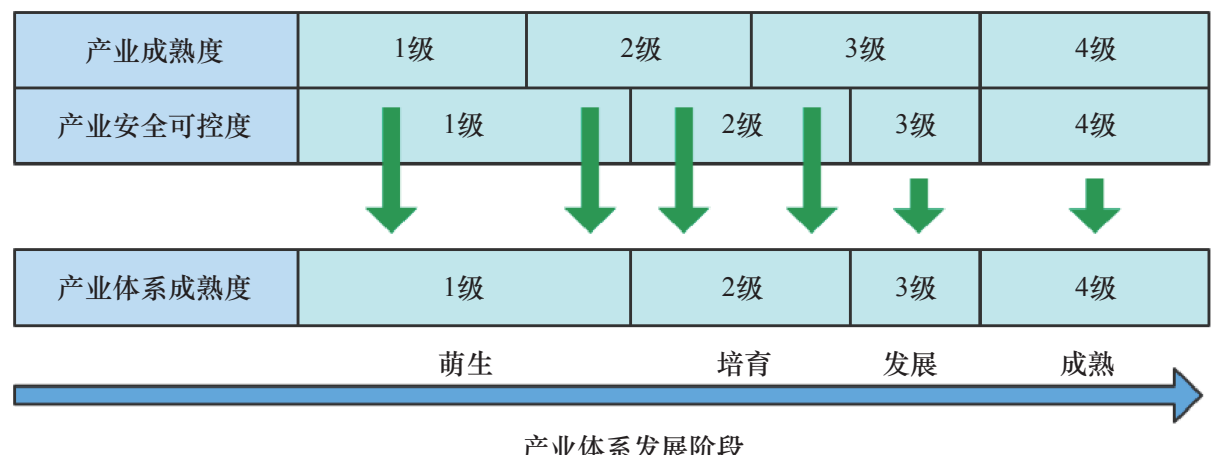

图 3 产业体系成熟度集成方法

\section{三、针对新兴产业的评估统计与分析}

\section{（一）总体评估情况}

应用产业体系成熟度评价模型, 组织完成了新 一代信息技术、高端装备、生物、新材料、绿色低 碳和数字创意 6 个领域、 25 个具体产业方向的成熟 度评价工作。相关评价过程分为 4 个阶段：(1)提出 成熟度评价工作的目标、思路和研究方法, 制定产 业体系成熟度自评价表单; (2)开展产业体系成熟度 评价方法的教育和培训; (3)组织各领域专家, 针对 本领域的若干产业方向开展评价, 填写产业体系成 熟度自评价表单; (4)基于各领域的自评价表单, 组 织专家开展综合评价和数据分析。25 个产业方向完 成的产业成熟度评价、产业体系成熟度评价结果见 表4。

\section{（二）评估结果分析}

在 25 个产业的产业成熟度方面，处于萌生阶 段的产业有 14 个，处于培育阶段的产业有 6 个; 还有 5 个产业进入了更高的阶段：风力发电、水污 染防治、太阳能光伏、超高清视频产业进入了发展 阶段, 纯电动汽车产业进入了成熟阶段。整体上, 多数产业的产业成熟度处于萌生阶段和培育阶段, 而进入发展和成熟阶段的产业数量偏少。

在 25 个产业的产业体系成熟度方面，处于萌 生阶段的产业有 15 个, 处于培育阶段的产业有 5 个; 还有 5 个产业进入了更高的阶段：风力发电、水污 染防治、太阳能光伏和超高清视频进入了发展阶段, 纯电动汽车产业进入了成熟阶段。整体上，25 个产 业的产业体系成熟度发展阶段与其所处的产业成熟 度发展阶段基本一致。
在 25 个产业的产业安全可控方面, 评价结果 整体不容乐观: 评价结果为弱的产业有 7 个, 评价 结果为较弱的产业有 8 个, 评价结果为中的产业有 9 个, 仅有纯电动汽车 1 个产业的评价结果为强。 在评价结果为弱的 7 个产业中, 轻薄化 AR 显示模 组, 生物医药、生物反应器及成套装置, 应急疫苗 研发与制备技术这 3 个产业, 其自主可控能力与行 业主导能力两个子指标评价结果均为弱, 表明产业 安全形势相对更为严峻。因而加强这些产业的自主 可控和行业主导能力显得尤为迫切。

针对 25 个产业, 具体梳理了未来发展亟待突 破的重点环节（见表 5)。共有 17 个产业存在亟 需突破环节，对应选取的判据为：若 $T R L<8$ 、 $M R L<9 、 M M L<2 、 I S C L<2$, 则认为在相应 环节需要突破。这一研究结果结合了微观和宏观因 素, 可为我国战略性新兴产业的行业研究和政策制 定机构提供直接参考。

\section{四、结语}

本文提出了产业体系成熟度概念，新增了包括 自主可控能力和行业主导能力在内的产业安全可控 程度评价因素，相应评价结果可以反映一国产业安 全可控程度的基本状况。对我国 25 个新兴产业方 向的产业体系成熟度评价分析表明，产业体系进入 发展或成熟阶段的产业方向数量相对较少, 且多数 产业方向的安全可控程度评价结果不佳。这一结论 为我国战略性新兴产业的优化发展提供了新的理论 支持。

对于安全可控程度评价结果不佳的产业方向, 应重点在核心原材料自主水平、核心技术自主水平、 
表 4 战略性新兴产业的产业成熟度和产业体系成熟度评价结果统计

\begin{tabular}{|c|c|c|c|c|c|c|c|c|c|c|}
\hline 领域 & 产业方向 & TRL & MRL & PRL & MML & $\begin{array}{l}\text { 产业 } \\
\text { 成熟度 }\end{array}$ & $\begin{array}{l}\text { 自主 } \\
\text { 可控 } \\
\text { 能力 }\end{array}$ & $\begin{array}{l}\text { 行业 } \\
\text { 主导 } \\
\text { 能力 }\end{array}$ & ISCL & $\begin{array}{l}\text { 产业 } \\
\text { 体系 } \\
\text { 成熟度 }\end{array}$ \\
\hline \multirow{2}{*}{$\begin{array}{l}\text { 信息 } \\
\text { 技术 }\end{array}$} & 轻薄化 AR 显示模组 & 7 & 7 & 3 & 1 & 1（萌生） & 1 & 1 & 1 & 1（萌生） \\
\hline & Micro LED 显示产业 & 7 & 7 & 3 & 1 & 1 （萌生） & 2 & 2 & 2 & 1 (萌生) \\
\hline \multirow{9}{*}{$\begin{array}{l}\text { 高端 } \\
\text { 装备 }\end{array}$} & 大型民机高端涂装产业 & 7 & 8 & 3 & 1 & 1（萌生） & 2 & 3 & 3 & 1 (萌生) \\
\hline & 石墨加工装备 & 7 & 9 & 3 & 2 & 1（萌生） & 2 & 2 & 2 & 1 (萌生) \\
\hline & 柔性显示面板激光加工 & 7 & 7 & 3 & 1 & 1（萌生） & 3 & 2 & 3 & 1（萌生） \\
\hline & 大型透平货油永系统 & 8 & 9 & 4 & 1 & 2 (培育) & 2 & 1 & 1 & 1 (萌生) \\
\hline & 大型高性能金属构件电弧熔丝增材制造 & 7 & 7 & 3 & 1 & 1（萌生） & 2 & 3 & 3 & 1 (萌生) \\
\hline & 深远海智能渔业养殖装备 & 8 & 9 & 4 & 1 & 2 (培育) & 3 & 2 & 3 & 2 (培育) \\
\hline & 智能数控机床 & 6 & 6 & 2 & 1 & 1（萌生） & 2 & 1 & 1 & 1 (萌生) \\
\hline & 电子束增材制造装备 & 7 & 7 & 3 & 1 & 1（萌生） & 2 & 1 & 1 & 1 (萌生) \\
\hline & $\begin{array}{c}\text { 化纤长丝卷装作业全流程智能化成套 } \\
\text { 技术装备 }\end{array}$ & 9 & 9 & 4 & 2 & 2 (培育) & 2 & 1 & 1 & 1 (萌生) \\
\hline \multirow[t]{3}{*}{ 生物 } & 生物基材料 & 7 & 8 & 3 & 1 & 1（萌生） & 2 & 2 & 2 & 1 (萌生) \\
\hline & 生物医药、生物反应器及成套装置 & 7 & 7 & 3 & 1 & 1（萌生） & 1 & 1 & 1 & 1 (萌生) \\
\hline & 应急疫苗研发与制备技术 & 7 & 7 & 3 & 1 & 1（萌生） & 1 & 1 & 1 & 1 (萌生) \\
\hline \multirow[t]{3}{*}{ 新材料 } & $\begin{array}{c}\text { 低维组合材料芯片高通量制备关键 } \\
\text { 技术与装备 }\end{array}$ & 6 & 7 & 2 & 1 & 1（萌生） & 2 & 2 & 2 & 1 (萌生) \\
\hline & 耐高温聚芳醚类高性能工程塑料 & 8 & 9 & 4 & 2 & 2 (培育) & 3 & 2 & 3 & 2 (培育) \\
\hline & 汽车用新一代先进超高强度钢 & 6 & 6 & 2 & 1 & 1（萌生） & 2 & 2 & 2 & 1 (萌生) \\
\hline \multirow{5}{*}{$\begin{array}{l}\text { 绿色 } \\
\text { 低碳 }\end{array}$} & 大气污染防治产业 & 9 & 9 & 4 & 2 & 2 (培育) & 2 & 2 & 2 & 2 (培育) \\
\hline & 风力发电产业 & 9 & 9 & 4 & 3 & 3 (发展) & 3 & 2 & 3 & 3 (发展) \\
\hline & 水污染防治产业 & 9 & 9 & 4 & 3 & 3 (发展) & 3 & 2 & 3 & 3 (发展) \\
\hline & 太阳能光伏产业 & 9 & 9 & 4 & 3 & 3 (发展) & 3 & 2 & 3 & 3 (发展) \\
\hline & 纯电动汽车产业 & 9 & 10 & 5 & 3 & 4 (成熟) & 3 & 3 & 4 & 4 (成熟) \\
\hline \multirow{3}{*}{$\begin{array}{l}\text { 数字 } \\
\text { 创意 }\end{array}$} & 虚拟现实产业 & 8 & 9 & 4 & 2 & 2 (培育) & 3 & 2 & 2 & 2 (培育) \\
\hline & 超高清视频产业 & 8 & 9 & 4 & 3 & 3 (发展) & 3 & 2 & 3 & 3 (发展) \\
\hline & 智能内容生成产业 & 6 & 5 & 2 & 1 & 1（萌生） & 2 & 2 & 2 & 1 (萌生) \\
\hline
\end{tabular}

注: AR 表示增强现实; Micro LED 表示微型发光二极管。

表 5 各产业方向有待重点突破环节统计

\begin{tabular}{lc}
\hline 产业方向 & 待突破环节 \\
\hline 轻薄化 AR 显示模组 & 技术、制造、市场、产业安全可控 \\
Micro LED 显示产业 & 技术、制造、市场、产业安全可控 \\
大型民机高端涂装产业 & 技术、制造、市场 \\
石墨加工装备 & 技术 \\
柔性显示面板激光加工 & 技术、制造、市场 \\
大型透平货油㫤系统 & 市场、产业安全可控 \\
大型高性能金属构件电弧熔丝增材制造 & 技术、制造、市场 \\
深远海智能渔业养殖装备 & 市场 \\
智能数控机床 & 技术、制造、市场、产业安全可控 \\
电子束增材制造装备 & 技术、制造、市场、产业安全可控 \\
化纤长丝卷装作业全流程智能化成套技术装备 & 产业安全可控 \\
\hline
\end{tabular}


（续表）

\begin{tabular}{lc}
\hline 产业方向 & 待突破环节 \\
\hline 生物基材料 & 技术、制造、市场 \\
生物医药、生物反应器及成套装置 & 技术、制造、市场、产业安全可控 \\
应急疫苗研发与制备技术 & 技术、制造、市场、产业安全可控 \\
低维组合材料芯片高通量制备关键技术与装备 & 技术、制造、市场 \\
汽车用新一代先进超高强度钢 & 技术、制造、市场 \\
智能内容生成产业 & 技术、制造、市场 \\
\hline
\end{tabular}

关键基础设备自主水平和资金自主水平等方面予以 加强, 从而提升产业的自主可控能力、解决 “卡脖 子”问题；注重提升国内品牌市场影响力、减少国 内产品销售对外出口依存度、提高行业标准制定水 平，从而增强行业主导能力。对于技术和制造成熟 度相对较高的产业方向，在着力提升产业安全可控 程度的同时，宜推广商业示范应用、加大政策扶持 力度来促进市场化发展，鼓励技术创新加速从科技 研发成果转化为大规模商业应用。

\section{参考文献}

[1] Mankins J. Technology readiness and risk assessments TRLs and innovation portfolio management history, practices and future directions [R]. Santa Maria: Artemis Innovation Management Solutions LLC, 2012.

[2] International Organization for Standardization. Space systemdefinition of the technology readiness levels (TRL) and their criteria of assessment: TC20/SC14/WG5 [S]. Geneva: International Organization for Standardization, 2011.

[3] 袁家军. 航天产品工程 [M]. 北京: 中国宇航出版有限责任公司, 2011.

Yuan J J. Aerospace product engineering [M]. Beijing: China Aerospace Publishing Co., Ltd., 2011.
[4] 吴燕生. 技术成熟度及其评价方法 [M]. 北京: 国防工业出版社, 2012.

Wu Y S. Technology readiness and its assessment method [M]. Beijing: China Aerospace Publishing Co., Ltd., 2012.

[5] Crawford J K. Project management maturity model [M]. New York: Auerbach Publications, 2006.

[6] 黎连业, 张晓冬, 吕小刚, 等. 软件能力成熟度模型与模型集成 基础 [M]. 北京: 机械工业出版社, 2011.

Li L Y, Zhang X D, Lv X G, et al. Software capability maturity model and model integration basis [M]. Beijing: China Machine Press, 2011.

[7] 张新国. 国防装备系统工程中的成熟度理论与应用 [M]. 北京: 国防工业出版社, 2013.

Zhang X G. Maturity theory and application in national defense equipment system engineering [M]. Beijing: National Defense Industry Press, 2013

[8] 王礼恒, 屠海令, 王芘声, 等. 产业成熟度评价方法研究与实践 [J]. 中国工程科学, 2016, 18(4): 9-17.

Wang L H, Tu H L, Wang K S, et al. Assessment of industry maturity levels: Research and practice $[\mathrm{J}]$. Strategic Study of CAE, 2016, 18(4): 9-17

[9] 产业成熟度编研组. 产业成熟度评价方法与应用 [M]. 北京: 中 国宇航出版有限责任公司, 2017.

Industry Maturity Editing and Research Group. Evaluation method and application of industrial maturity levels [M]. Beijing: China Aerospace Publishing Co., Ltd., 2017. 